Témoigner Témoigner. Entre histoire et mémoire

Getuigen Revue pluridisciplinaire de la Fondation Auschwitz

$122 \mid 2016$

Révisionisme et négationisme

\title{
Pierre-Jérôme Biscarat, Izieu, des enfants dans la Shoah
}

Colette Gutman

\section{Q OpenEdition}

1 Journals

Édition électronique

URL : https://journals.openedition.org/temoigner/4735

DOI : $10.4000 /$ temoigner.4735

ISSN : 2506-6390

Éditeur :

Éditions du Centre d'études et de documentation Mémoire d'Auschwitz, Éditions Kimé

Édition imprimée

Date de publication : 2 mai 2016

Pagination : 177

ISSN : 2031-4183

Référence électronique

Colette Gutman, «Pierre-Jérôme Biscarat, Izieu, des enfants dans la Shoah », Témoigner. Entre histoire et mémoire [En ligne], 122 | 2016, mis en ligne le 30 septembre 2021, consulté le 03 janvier 2022. URL : http://journals.openedition.org/temoigner/4735 ; DOI : https://doi.org/10.4000/temoigner.4735

Ce document a été généré automatiquement le 3 janvier 2022.

Tous droits réservés 


\title{
Pierre-Jérôme Biscarat, Izieu, des enfants dans la Shoah
}

\author{
Colette Gutman
}

\section{RÉFÉRENCE}

Pierre-Jérôme Biscarat, Izieu des enfants dans la Shoah, Paris, Fayard, 2014, 330 p.

1 C'est un livre qu'on lit la gorge serrée, c'est le récit global et détaillé d'une tragédie qui s'est déroulée le 6 avril 1944, lorsque la Gestapo de Lyon, sous le commandement de Klaus Barbie, a arrêté pour les déporter quarante-quatre enfants juifs d'Europe, pour la plupart orphelins, de cinq à dix-sept ans, et leurs sept éducateurs, dans un petit village au bout du monde sur les contreforts du Jura. Aucun enfant n'est revenu. Le procès de Klaus Barbie a eu lieu en 1987. Un Musée Mémorial a été inauguré en 1994 par le Président François Mitterrand. Ce livre de Pierre-Jérôme Biscarat suit les parcours qu'il a pu reconstituer à l'aide de documents, de lettres, de témoignages.

2 La colonie d'Izieu a été créée en 1943 par Sabine et Miron Zlatin, en lien avec l'đuuvre de Secours aux Enfants (O S E). Leurs noms - une militante juive polonaise et un ingénieur juif russe - figurent maintenant sur des plaques de rues à travers la France. Ce livre décrit le contexte, le cadre, les relations avec l'Administration française, et les destins des familles brisées par les départs, les séparations, et la destination finale. Aujourd'hui, le Musée Mémorial accueille chaque année des milliers de scolaires et participe à leur éducation citoyenne - en hommage à Sami (2 ans), Otto (8 ans et demi), Fritz (11 ans), Théo (12 ans et demi) et les autres... C'est ici que Paul a fêté son $13^{\mathrm{e}}$ anniversaire.

3 La vie s'organise. Egon Gamiel (8 ans), Otto Wertheimer (10 ans), Fritz Loebmann (13 ans) se trouvent à la colonie, leurs parents ayant été déportés, comme ceux de Liliane et Renate Krochmal ( 5 et 7 ans), Émile Zukerberg ( 5 ans), Martha et Senta Spiegel (7 et 5 ans), Sigmund Springer ( 6 ans), Theo Reiss (14 ans)... L'encadrement éduque, distrait, motive, donne des règles de vie, apprend à lire aux plus jeunes. Sabine 
et Miron Zlatin s'occupent des questions matérielles. On y dispense une éducation, le personnel de la colonie répartit les rôles. Paulette Pallarès est chargée d'endormir les petits : «Émile, il fallait l'endormir. C'était un petit blond avec des yeux très bleus, avec toujours des vêtements bleus. Il était mignon, adorable, mais alors il était traumatisé parce qu'il avait vu arrêter ses parents », Émile, dont les parents avaient été arrêtés par des gendarmes français, veut tuer tous les gendarmes.

4 Tout proche du petit village de 170 habitants, le paysage est à couper le souffle, les couchers de soleil ressemblent au paradis, la maison date de la fin du XIX ${ }^{\mathrm{e}}$ siècle : deux étages, un jardin avec des arbres fruitiers. Les relations avec le voisinage sont bonnes.

L'atmosphère de l'été est particulièrement détendue, ce sont les vacances. Claude Raiz : «Et ben oui! Ça, c'était une colonie de vacances. Ah, c'était magnifique [...] On plongeait dans le bassin. On se faisait sécher. On rigolait." D'où est venue la dénonciation? Rien n'est clair, mais l'un des suspects a été condamné à la dégradation nationale à vie. 